\title{
The Wind Test on Heat Loss from Three Coil Cavity Receiver for a Parabolic Dish Collector
}

\author{
Ramola Sinha ${ }^{1, *}$, Nitin P. Gulhane ${ }^{1}$, Pawet Ocłoń $^{2}$, Jan $_{\text {Taler }}{ }^{2}$ and Rahimi Gorji ${ }^{3}$ \\ ${ }^{1}$ Department of Mechanical Engineering, VJTI, Matunga, Mumbai, 400019, India \\ ${ }^{2}$ Institute of Thermal Power Engineering Cracow University of Technology,Poland \\ ${ }^{3}$ Ghent University, Belgium
}

\begin{abstract}
The heat loss from cavity receiver in parabolic dish system determines the efficiency and cost effectiveness of the system. A modified three coil solar cavity receiver of inner wall area approximately three times of single coil receiver, is experimentally investigated to study the effect of fluid inlet temperature $\left(\mathrm{Tfi}=50^{\circ} \mathrm{C}\right.$ to $75^{\circ} \mathrm{C}$ ) and cavity inclination angle $\left(\theta=0^{\circ}\right.$ to $\left.90^{\circ}\right)$ on the heat loss from receiver under wind condition for head on wind and side on wind velocity at $3 \mathrm{~m} / \mathrm{s}$. Overall it was found that the natural and forced convection total heat loss increases with increase in mean fluid temperature. The combined heat loss decreases sharply with the increase in cavity inclination and observed to be maximum for horizontal position of receiver and minimum with the receiver facing vertically downward for all investigations. The maximum heat loss in wind test $(\mathrm{V}=3 \mathrm{~m} / \mathrm{s})$ is $1045 \mathrm{~W}$ at $\theta=0^{\circ}$ cavity inclination at mean fluid temperature $68^{\circ} \mathrm{C}$ and minimum at $173 \mathrm{~W}$ $\theta=90^{\circ}$ at $53^{\circ} \mathrm{C}$. Total heat loss from the receiver under wind condition $(\mathrm{V}=3 \mathrm{~m} / \mathrm{s})$ is up to $25 \%$ higher $(1.25$ times at $0^{\circ}$ inclination) than without wind at mean fluid temperature $\sim 70^{\circ} \mathrm{C}$ and minimum $19.64 \%\left(1.2\right.$ times at $90^{\circ}$ inclination) in mean temperature $\sim 50{ }^{\circ} \mathrm{C}$. In horizontal position of the receiver $\left(\theta=0^{\circ}\right)$, the total heat loss by head on wind is about 1.23 times $\left(18 \%\right.$ higher ) as compared to side on wind (at fluid mean temperature $\left.\sim 70^{\circ} \mathrm{C}\right)$. For receiver facing downward $\left(\theta=90^{\circ}\right)$, for head-on wind, total heat loss is approximately the same as that for side-on wind.
\end{abstract}

\section{Introduction}

The parabolic dish-receiver assembly is suitable for supplying heat for process applications as well as generating power. It consists of a paraboloid dish with downward facing receiver at the focus. Generally, a cavity receiver is used to capture the flux at focus since it has low heat loss (Harris and Lenz) [1].

Natural convection heat loss from solar cavity receiver is investigated by many researchers. A very few investigation are carried out with wind effects and hence forced convection on receiver heat loss. However in actual field, wind can considerably affect the thermal performance of the cavity receiver.

\footnotetext{
*Correspondence author: ramolasinha@somaiya.edu
}

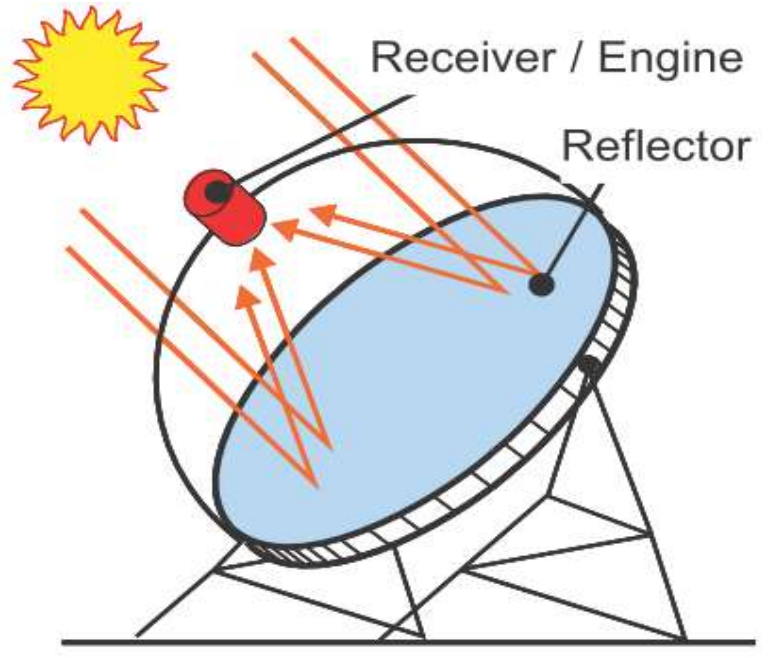

Fig. 1. Schematic diagram of parabolic dish receiver dish receiver system [1]. 
The result of experimental investigation on wind test conducted by Faust et al. [2] showed that a small value of wind velocity $(0.89 \mathrm{~m} / \mathrm{s})$ shows marginable increase in convection heat loss from the receiver. It was observed that wind parallel to the aperture plane results in the highest convective heat loss. Ma [3] had experimentally investigated the convection heat loss under wind conditions for a mouth-blocked cylindrical cavity with conical frustum. The tests were carried out for various receiver inclinations under wind speeds between 3 and $10 \mathrm{~m} / \mathrm{s}$. The wind tests were carried out under head-on (at any cavity inclination, wind direction is parallel to the ground while it blows through the aperture of the cavity) and side-on (at any cavity inclination, wind direction is parallel to the ground and is perpendicular to the head-on condition). The value of convective heat loss during wind test was higher than the no-wind case. The value of convection heat loss during wind test at $10 \mathrm{~m} / \mathrm{s}$ was about three times the value of the no-wind condition. It was observed that side-on wind causes higher convective loss than head-on.

Kugath et al. [4] investigated the effects of wind $(4.47 \mathrm{~m} / \mathrm{s})$ on convective heat loss from cylindrical cavity with conical frustum. It was observed that the convective heat loss is dependent upon receiver inclination. The convection heat loss was observed highest during head on wind (wind blowing directly into the cavity) and was four times that of convective heat loss under natural convection.

Prakash et al. [5] had carried out experimental investigation on downward facing cylindrical cavity receiver with wind skirt for two wind speed $(1 \mathrm{~m} / \mathrm{sec}$ and $3 \mathrm{~m} / \mathrm{s})$ and two directions (head-on and side-on).

They have reported, in contrast to Ma [3], that the head-on wind causes higher convective loss as compared to the sideon wind. Shuang-Ying Wu et al. [6] have also reported such conflicting results. Lee et al.[7] had investigated the effect of aspect ratio and head-on wind speed on the force and natural (combined) convective heat loss using three dimensional computational fluid dynamics (CFD) simulations.

It has been observed that, under uniform temperature of the cavity walls, up to a certain lower critical velocity (higher than $2 \mathrm{~m} / \mathrm{sec}$ ) the combined convective heat loss is below the value for the natural convection (i.e. a wind speed of zero). Furthermore, convection heat loss per unit area under wind condition reduces with the increase in aspect ratio. However, the heat flux (heat loss per unit area) of the combined convective loss drops by approximately $74 \%$ when the aspect ratio is increased from 0.5 to 3 for a wind speed of $10 \mathrm{~m} / \mathrm{s}$. It concluded that the overall efficiency of a solar cavity receiver increases with the increases with the aspect ratio of the cavity receiver.

The heat loss from cavity receiver determines thermal efficiency of the receiver used. The overall parabolic dish concentrator efficiency depends upon the efficiency of the receiver used. An understanding of the various modes of heat transfer from the receiver is required in order to adequately predict receiver efficiency. Radiation and conduction heat losses from the receiver can be predicted reasonably well by analytical techniques; however, convection from the cavity is much more complicated and difficult to predict analytically. Wind effects and varying receiver inclination make it an even more difficult phenomenon to predict analytically.

It is observed from the literature that the convective heat transfer constitutes a major share of the thermal losses [5, $8,9]$. The convective losses from these solar cavity receivers are found to be dependent on various parameters like receiver inclination $(\theta)$, receiver wall boundary condition, aspect ratio $(L / D)$, opening ratio $(d / D)$, and external wind. This is the reason due to which analysis of convective losses from solar cavity receivers is complicated when compared to that of heat transfer due to radiation and conduction.

In the present work, the experimental investigation on three coil cylindrical cavity receiver is extensively carried out at low temperature (sub cooled water below $100{ }^{\circ} \mathrm{C}$ ), suitable for process heat applications and combined (total) heat loss between cavity receiver and ambient air under wind condition is measured. The inner wall area to aperture area ratio (area ratio, $\mathrm{A}_{\text {wicav }} / A_{a p}$ ) of the three coil receiver is approximately 3 times the single coil receiver. The objective of this work is to study the effect of the fluid inlet temperature $\left(T_{f i}\right)$ and cavity inclination $(\theta)$ on heat loss from three coil cavity receiver under head on wind and side on wind at $3 \mathrm{~m} / \mathrm{sec}$.

\section{Materials and Methods}

\subsection{Description of the receiver}

The three coil cavity receiver is made of a highly polished copper tube of outer diameter $11 \mathrm{~mm}$ and thickness $1 \mathrm{~mm}$ wounded around to form a cylindrical shape of outer coil diameter $0.33 \mathrm{~m}$ and height $0.50 \mathrm{~m}$ structure with a skirt of diameter $0.50 \mathrm{~m}$ and height $80 \mathrm{~mm}$. The two inner helical coils (enclosed inside outer coil) are made of mean diameter of $0.27 \mathrm{~m}$ (middle coil) and $0.20 \mathrm{~m}$ (inner coil) respectively, with the coil height $0.38 \mathrm{~m}$ and supported on the provision made for it.

The three coils are internally connected and the average clearance between the tubes is 2-3 mm. Except two inner coils, this design is similar to receiver used in a parabolic dish-receiver system for supplying process heat.The figure 2 shows the actual receiver front and side view and figure 3 shows the longitudinal and circumferential location of 10 thermocouples in the receiver.

*Correspondence author: ramolasinha@somaiya.edu 

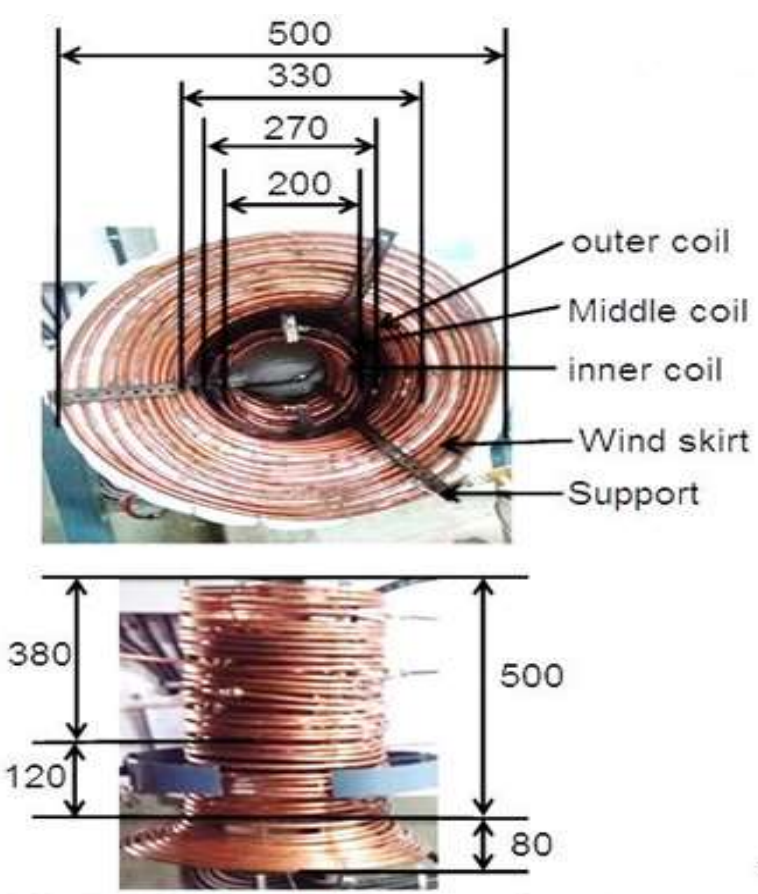

All dimensions in $\mathrm{mm}$

Fig. 2. Three coil cavity receiver actual front and side view

Ten K-type thermocouples are used to measure fluid temperatures at the different locations of the receiver (Fig.3). The temperature is measured by 12 points manual temperature indicator. A $20 \mathrm{~mm}$ thick circular ceramic fiber insulation board of density $280 \mathrm{~kg} / \mathrm{m} 3$ and thermal conductivity $0.11 \mathrm{~W} / \mathrm{m} . \mathrm{K}$ is used on the back side of the receiver. The receiver is covered from all sides (except aperture area), with $6 \mathrm{~cm}$ thick glass wool insulation, which minimizes the heat loss by conduction and maintains the outer layer of the insulation at nearly ambient temperature (insulated).

The cavity dimensions and material properties are given in table 1 and 2.

Table 1. Geometrical dimensions

\begin{tabular}{|l|c|c|}
\hline Nomenclature & Symbol & Dimensions \\
\hline Mean diameter of outer coil & $\mathrm{D}_{\text {icav1 }}$ & $0.33 \mathrm{~m}$ \\
\hline Mean diameter of middle coil & $\mathrm{D}_{\text {icav2 }}$ & $0.27 \mathrm{~m}$ \\
\hline Mean diameter of inner coil & $\mathrm{D}_{\text {icav3 }}$ & $0.20 \mathrm{~m}$ \\
\hline Aperture diameter & $\mathrm{D}_{\text {ap }}$ & $0.33 \mathrm{~m}$ \\
\hline Length of outer coil & $\mathrm{L}_{\text {icav1 }}$ & $0.50 \mathrm{~m}$ \\
\hline Length of middle coil & $\mathrm{L}_{\text {icav2 }}$ & $0.38 \mathrm{~m}$ \\
\hline Length of inner coil & $\mathrm{L}_{\text {icav3 }}$ & $0.38 \mathrm{~m}$ \\
\hline
\end{tabular}

*Correspondence author: ramolasinha@somaiya.edu
Table 2. Copper and glass wool properties at $100^{\circ} \mathrm{C}$

\begin{tabular}{|l|c|c|}
\hline Material & Copper $(\mathbf{C u})$ & $\begin{array}{c}\text { Glass } \\
\text { wool }\end{array}$ \\
\hline Density $(\rho), \mathrm{kg} / \mathrm{m}^{3}$ & 8933 & 120 \\
\hline $\begin{array}{l}\text { Thermal Conductivity }(\mathrm{k}), \\
\mathrm{W} / \mathrm{m}^{2} . \mathrm{K}\end{array}$ & 395.7 & 0.04 \\
\hline Emissivity & 0.03 & -- \\
\hline
\end{tabular}

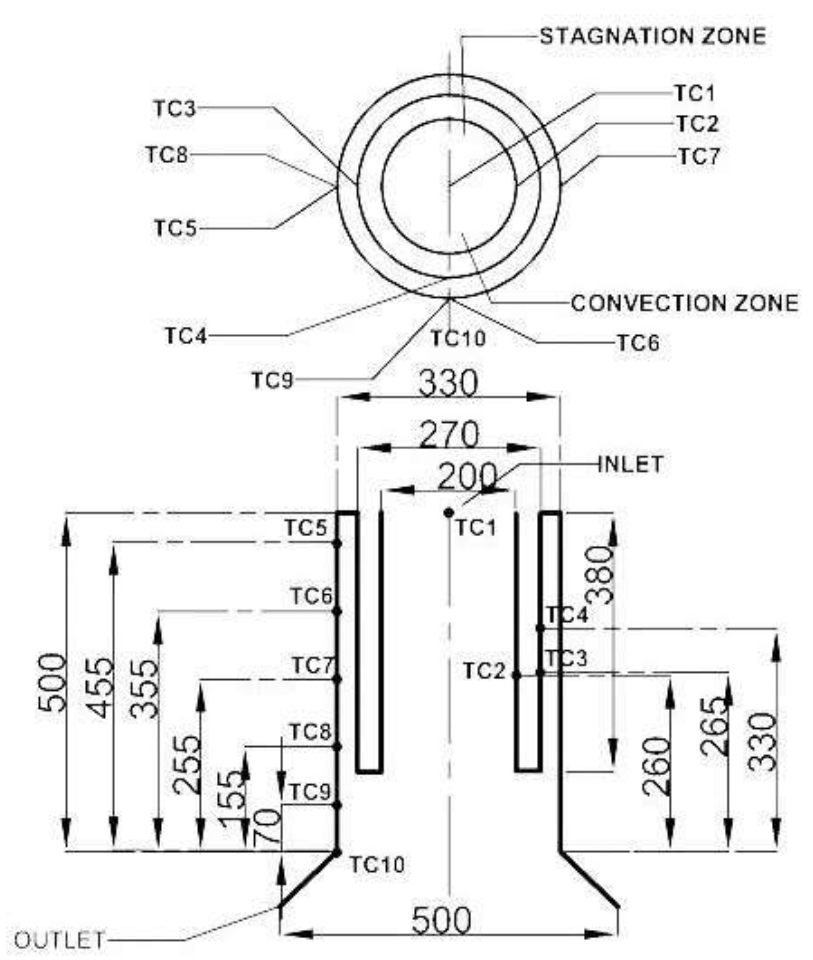

Fig. 3. Longitudinal and circumferential locations of thermocouples in three coil cavity receiver.

\subsection{Experimental investigation}

The experimental investigation of heat loss from solar cavity receiver is conducted either in on flux mode (field test) or off flux mode (simulated experiments in laboratory). To simulate with the field test in the actual condition, hot water at constant temperature is supplied to the inlet of the cavity receiver from the top at constant mass flow rate under different cavity inclinations.

The boundary conditions used for the analytical analysis are: the inlet temperature and the velocity of the working fluid are specified, adiabatic condition is assumed for the cavity insulation; cylindrical enclosure walls are maintained at ambient temperature of $30^{\circ} \mathrm{C}$. Receiver wall temperature is assumed as mean fluid temperature of the fluid. 
The experimental setup for natural convection (no wind) and forced convection (wind test) is shown in Fig.4 and Fig. 5 respectively.

To simulate with the field test in the actual condition, hot water at constant temperature $\left(50-75^{\circ} \mathrm{C}\right)$ is supplied to the inlet of the cavity receiver from the top of the receiver, at constant mass flow rate $(0.02 \mathrm{~kg} / \mathrm{sec}$ approx. $)$ under different cavity inclinations $\left(0^{\circ}, 30^{\circ}, 45^{\circ}, 60^{\circ}\right.$ and $\left.90^{\circ}\right)$ at wind speed $3 \mathrm{~m} / \mathrm{sec}$. Achieving steady state takes 3-4 hours, when the outlet temperature remains steady for about half an hour to one hour.

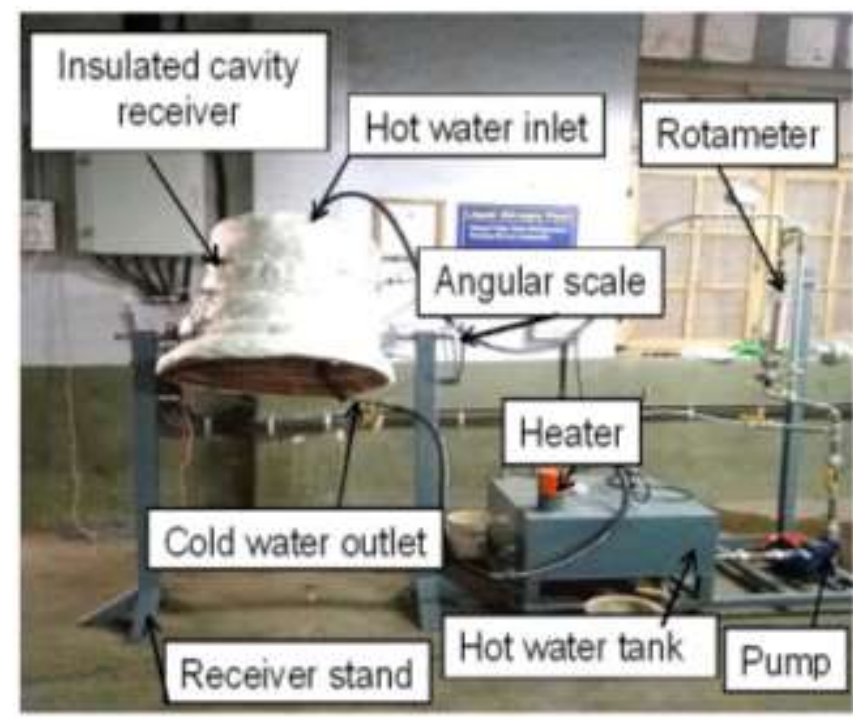

Fig. 4. Three coil cavity receiver experimental setup

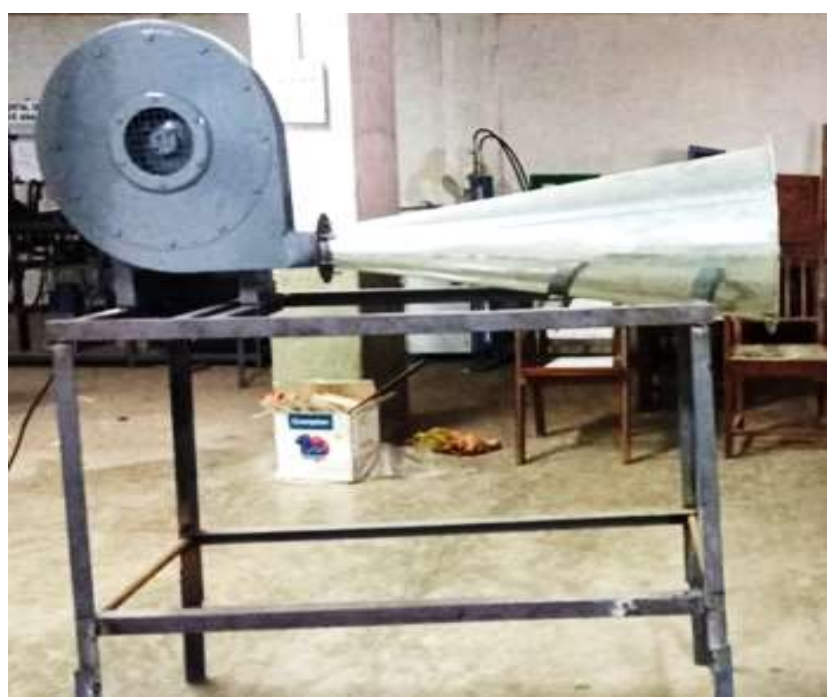

Fig. 5. Three coil cavity receiver wind test setup.

The wind is supplied through the wind tunnel (Fig.5) The wind velocity is simulated by using air from blower through a wind tunnel at velocity $3 \mathrm{~m} / \mathrm{sec}$. The test is carried out under head on wind (wind direction heading towards the opening of cavity) and side on wind (wind direction perpendicular to the opening of cavity) as shown in figure 6.

\section{Side on wind}

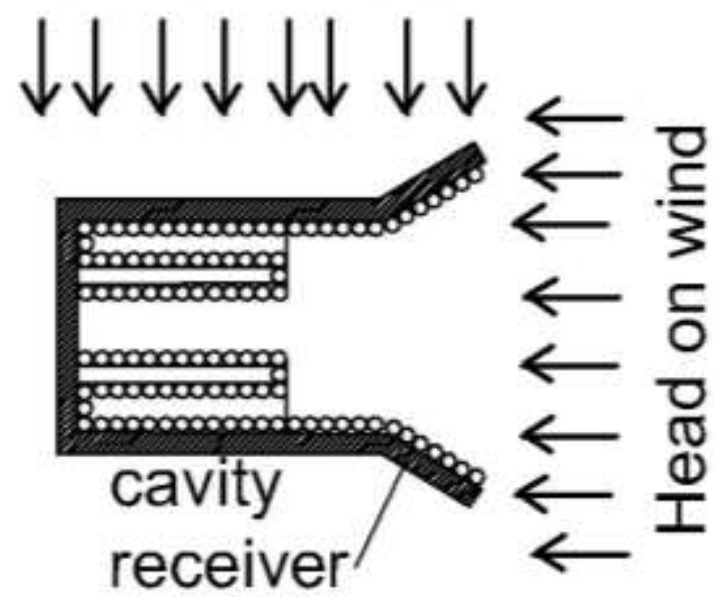

Fig. 6. Wind direction convention: Side \& head on wind

\section{Total Heat Loss Analysis}

The evaluation of the thermal losses from three modes of heat transfer (conduction, convection and radiation) is a determining factor in the optimization of the receiver. It is important to assess this heat loss and subsequently improve the thermal performance of the system.

\subsection{Receiver heat balance}

In the steady state condition useful heat gain is zero and heat received from solar radiation is total heat lost from the receiver, the heat balance is given by:

$$
\begin{gathered}
Q_{\text {in }}=Q_{t c a v} \\
Q_{\text {tcav }}=Q_{\text {ccav }}+Q_{\text {rcav }}+Q_{c o n d r}+Q_{c o n d b}
\end{gathered}
$$

During the simulation testing, at steady state heat supplied to the receiver is heat loss from the receiver. The total heat loss from the receiver is the sum of conduction, convection and radiation. Where $Q_{\text {ccav }}, Q_{\text {rcav }}, Q_{\text {condr }}$ and $Q_{\text {condb }}$ is the convective, radiation, conductive heat loss from back side and radial direction of the receiver. Where $Q_{\text {tcav }}$ the total is is (combined) heat loss from receiver. The heat losses from three coil cavity receiver are shown in figure 7.

*Correspondence author: ramolasinha@,somaiya.edu 


\subsection{Total heat loss from the receiver}

The steady state outlet temperature and mass flow rate of the working fluid are obtained from each experiment performed in the investigation. The combined heat loss from natural convection and forced convection (Wind test) heat loss is then calculated from the experimental data is (Fig.7):

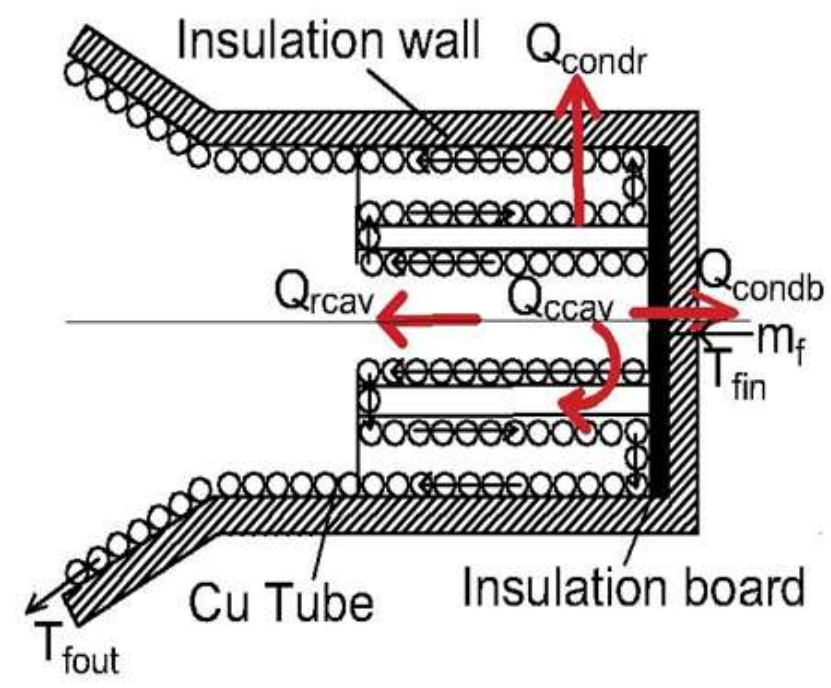

Fig. 7. Description of heat losses of the cylindrical cavity receiver

$$
\begin{gathered}
Q_{\text {tcav }}=\dot{m}_{f} C_{p}\left(T_{\text {fin }}-T_{\text {fout }}\right) \\
Q_{\text {tcav }}=Q_{\text {ccav }}+Q_{\text {rcav }}+Q_{\text {condr }}+Q_{\text {condb }}
\end{gathered}
$$

Where $T_{\text {fin }} \& T_{\text {fout }}$ is fluid inlet and outlet temperature and $\dot{m}_{f}$ is mass flow rate of the fluid through the receiver as shown in Fig. 4 and receiver dimension in Fig.8.

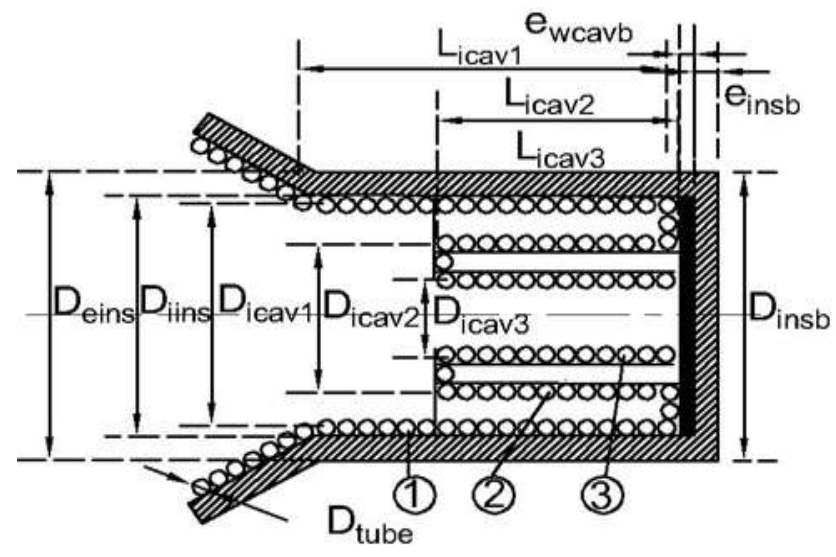

\section{Results and Discussion}

\subsection{Variation of head on wind (forced convection) total heat loss with mean fluid temperature}

The forced convection (head on wind) heat loss increases linearly with the increase of mean fluid temperature for all cavity inclinations (Fig.9). The forced convection heat loss decreases with the increase of cavity inclination angle when mean fluid temperature is constant; this may be because with the increasing inclination flow of hot air from inside of the cavity is difficult. When the cavity is horizontal $\left(\theta=0^{0}\right)$ the enhanced buoyancy force easily removes the heated air trapped inside the cavity and results in highest convection heat loss. For the vertical position of the cavity $\left(\theta=90^{\circ}\right)$, convection is suppressed to give lowest convection heat loss. Head on wind forced convection heat loss is maximum at $0^{\circ}$ inclination (maximum loss $1045 \mathrm{~W}$ at $68^{\circ}$ mean fluid temperature) and minimum at $90^{\circ}$ inclination (minimum loss $173 \mathrm{~W}$ at $53{ }^{\circ} \mathrm{C}$ ) for mean temperature between $50-70^{\circ} \mathrm{C}$ (Fig. 9).

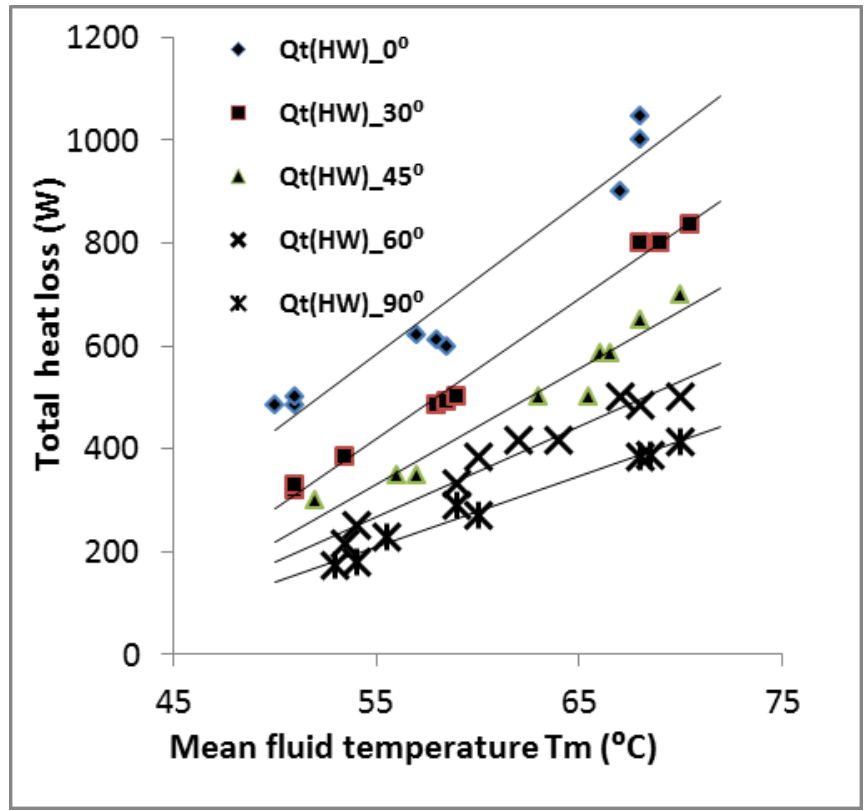

Fig. 9. Variation of head on wind (forced convection) total heat loss with mean fluid temperature at various cavity inclinations $\left(\theta=0-90^{\circ}\right)$

\subsection{Comparison of forced convection heat loss from head on wind with side on wind}

Figure 10 and 11 shows the comparison of head on wind with side on wind combined heat loss with fluid mean temperature.

Fig. 8. Three coil cavity receiver dimension 


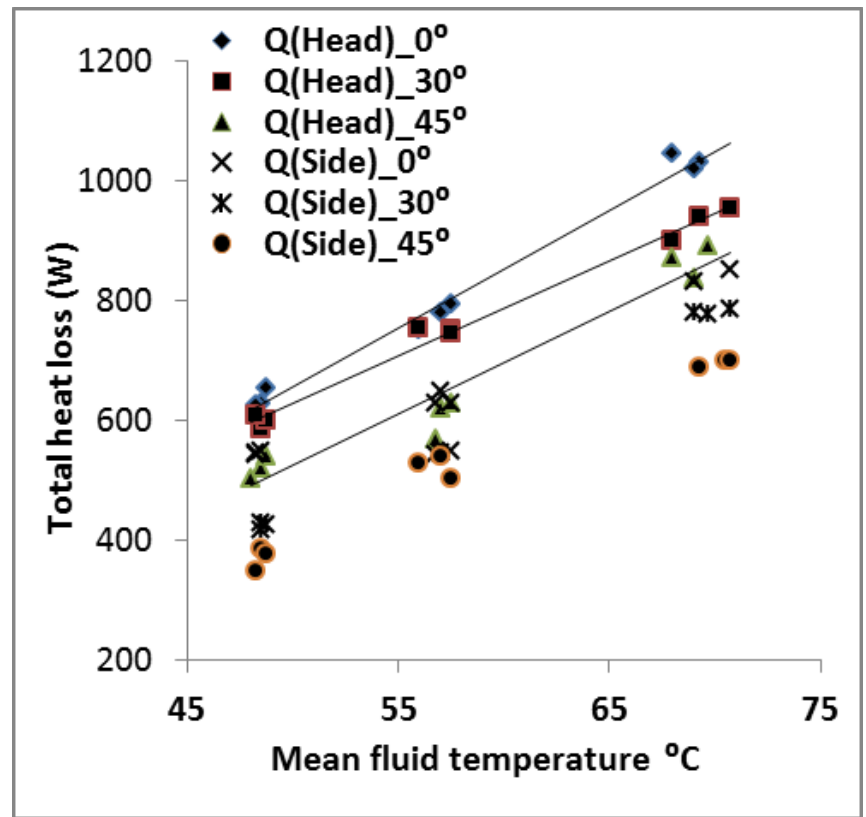

Fig. 10. Comparison of head on wind and side on wind total heat loss with mean fluid temperature at cavity inclination $\theta=0-45^{\circ}$.

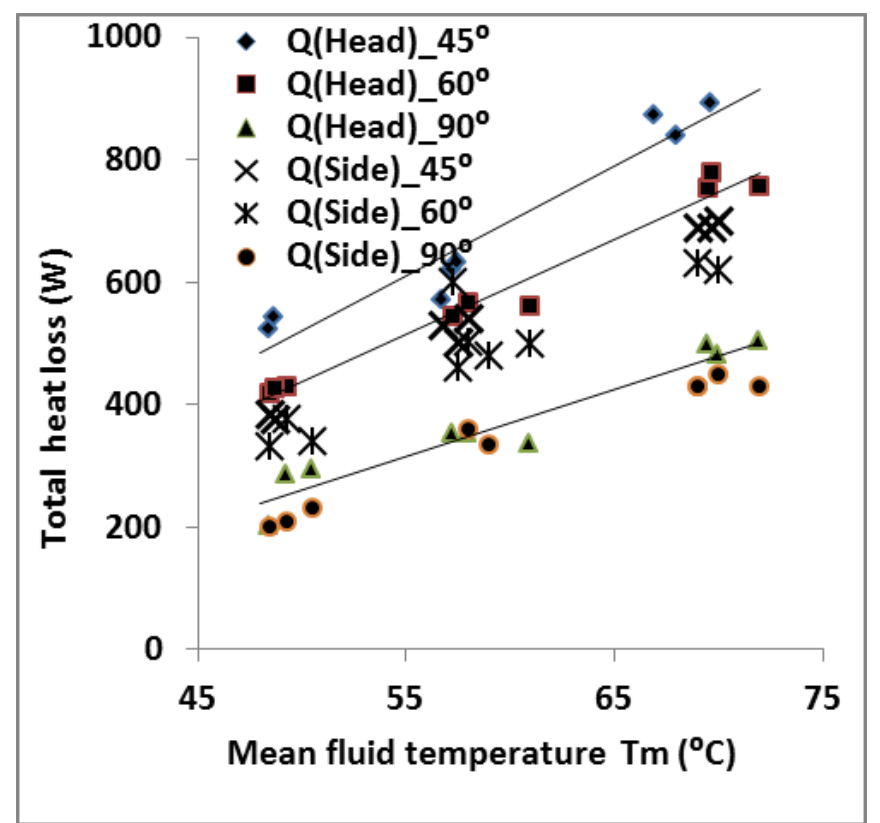

Fig.11. Comparison of head on wind and side on wind total heat loss with mean fluid temperature at cavity inclination $\theta=45-90^{\circ}$

Forced convection total heat loss increases with increase in fluid mean temperature. Forced convection heat loss is maximum at $0^{\circ}$ for all temperature between $50-70^{\circ} \mathrm{C}$. With the receiver facing horizontally with opening in vertical plane $\left(\theta=0^{\circ}\right)$, the head on wind heat loss is $\sim 19 \%$ higher than the side on wind. The head on wind forced convection heat loss $1045 \mathrm{~W}$ at $68{ }^{\circ} \mathrm{C}$ as compared to side on wind 850 W $70{ }^{\circ} \mathrm{C}$ (Fig.10).

For the vertically downward facing receiver with opening in horizontal plane $\left(\theta=90^{\circ}\right)$, the head on wind heat loss is 0 -
$13 \%$ higher in mean temperature range $50-70{ }^{\circ} \mathrm{C}$. This is because at vertical position of receiver, convection of hot air is restricted and heat loss is mainly because of the mean temperature of the receiver. The head on wind forced convection heat loss $501.6 \mathrm{~W}$ as compared to side on wind is $430 \mathrm{~W}$ at $72{ }^{\circ} \mathrm{C}(13 \%$ higher $)$ and $209 \mathrm{~W}$ at mean fluid temperature $\sim 50{ }^{\circ} \mathrm{C}$ for both the cases of head on wind and side on wind (Fig.11).

\subsection{Comparison of natural convection heat loss with forced convection (HW)}

Figure 12 shows receiver natural and forced convection combined heat loss as a function of cavity inclination $(\theta)$ for natural convection (NC) and forced convection (HW) total heat loss for mean fluid temperature between 50 $70^{\circ} \mathrm{C}$.

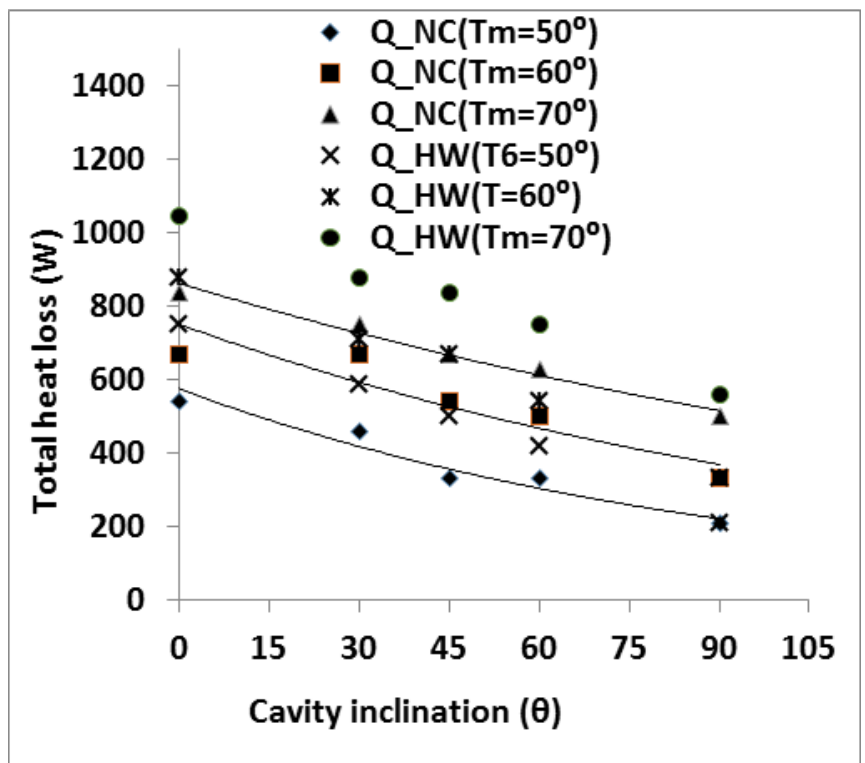

Fig.12. Comparison of natural convective with forced convection (HW) total heat loss with cavity inclination at mean fluid temperature $\mathrm{Tm}=50-70^{\circ} \mathrm{C}$.

The natural convection and forced convection (HW) combined heat decreases significantly with increase in cavity inclination at constant mean fluid temperature. The convective heat loss from the receiver is the highest with the receiver facing horizontally $\left(\theta=0^{\circ}\right)$ and lowest with the receiver facing straight down $\left(\theta=90^{\circ}\right)$.

With the receiver facing horizontally $\left(\theta=0^{\circ}\right)$, the value of maximum natural convective heat loss is approximately $836 \mathrm{~W}$ and forced convection $1045 \mathrm{~W}$ (at fluid mean temperature $\sim 70^{\circ} \mathrm{C}$ ). With the receiver facing straight down $\left(\theta=90^{\circ}\right)$, the value of maximum natural convective heat loss is approximately $501.6 \mathrm{~W}$ and forced convection (HW) $600 \mathrm{~W}$ (at fluid mean temperature $70^{\circ} \mathrm{C}$ ). Interpretation of the phenomenon can be explained as follows: In horizontal position of the cavity, maximum 
area of receiver falls in convection zone and the convection heat loss is observed maximum with the minimum cavity temperature. However opposite to this, at vertical position of receiver cavity convection zone is minimum and temperature of cavity is maximum [10].

\subsection{Comparison of head on wind (HW) forced convection heat loss to side on wind (SW)}

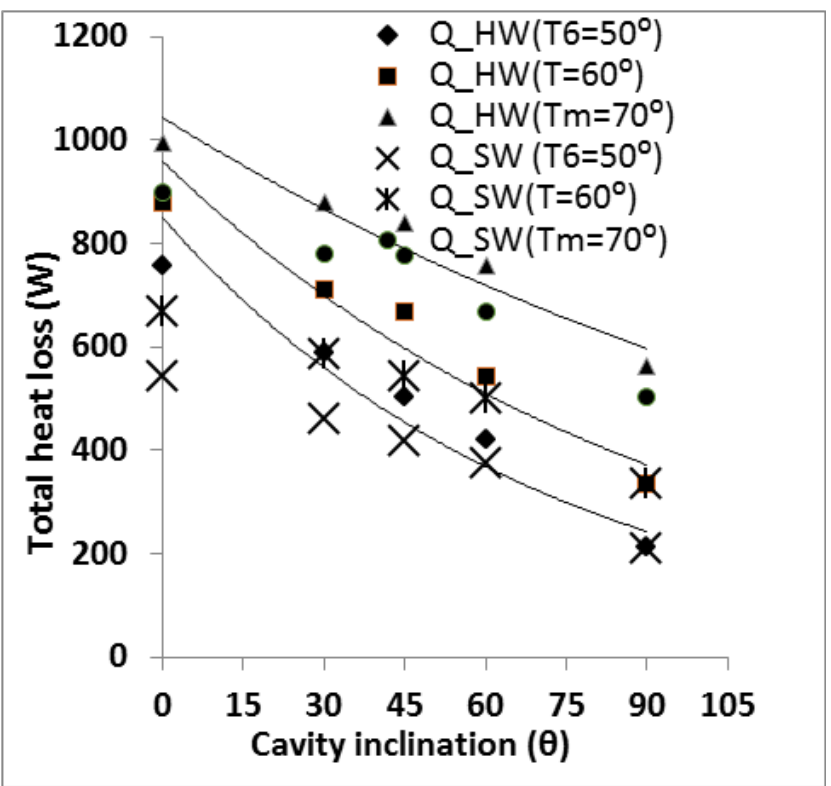

Fig. 13. Comparison head on wind and side on wind forced convective total heat with cavity inclination

Figure 13 presents receiver convection heat loss as a function of cavity inclination $(\theta)$ for head on wind (HW) and side on wind (SW) for mean fluid temperature between $50-70^{\circ} \mathrm{C}$. With the receiver facing horizontally $\left(\theta=0^{\circ}\right)$, the value of maximum side on wind heat loss is approximately $900 \mathrm{~W}$ and head on wind convection heat loss $1045 \mathrm{~W}$ (at fluid mean temperature $\sim 70^{\circ} \mathrm{C}$ ). The maximum total heat loss at $\left(\theta=90^{\circ}\right)$ for $\mathrm{HW}$ and side on wind is $560 \mathrm{~W}$ and 501 $\mathrm{W}$ at (at fluid mean temperature $\sim 50^{\circ} \mathrm{C}$ )

\section{Conclusions}

Generally speaking, natural convective currents flow inside the receiver from bottom to top, in a vertical plane. For side-on winds, forced convective currents are generally in a direction normal to the plane of natural convective currents. Because of this orthogonal relationship between natural and forced convective currents, it is reasonable to hypothesize that forced convection from the receiver is independent of natural convection. Overall it was found that the natural and forced convection total heat loss increases with increase in mean fluid temperature. The total heat loss decreases with increase in cavity inclination. The maximum heat loss in

*Correspondence author: ramolasinha@,somaiya.edu wind test $(\mathrm{V}=3 \mathrm{~m} / \mathrm{s})$ is $1045 \mathrm{~W}\left(\theta=0^{\circ}\right)$ cavity inclination at mean fluid temperature $68{ }^{\circ} \mathrm{C}$ and minimum at $173 \mathrm{~W}$ $\left(\theta=90^{\circ}\right)$ at $53^{\circ} \mathrm{C}$

Total heat loss from the receiver under wind condition $(\mathrm{V}=3 \mathrm{~m} / \mathrm{s})$ is up to $25 \%$ higher $\left(1.25\right.$ times at $0^{\circ}$ inclination) than without wind at mean fluid temperature $\sim 70^{\circ} \mathrm{C}$ and minimum $19.64 \%$ (1.2 times at $90^{\circ}$ inclination) in mean temperature $\sim 50{ }^{\circ} \mathrm{C}$.

In horizontal position of the receiver $\left(\theta=0^{\circ}\right)$, the total heat loss by head on wind is about $1.23(18 \%)$ times as compared to side on wind (at fluid mean temperature $70^{\circ} \mathrm{C}$ ). For head-on wind, total heat loss with the receiver facing straight down is $\left(\theta=0^{\circ}\right)$ is approximately the same as that for side-on wind.

\section{Acknowledgments}

This experimental work was financially supported by the research grant of Veermata Jijabai Technological Institute, Mumbai.

\section{References}

1. J.A. Harris, T.G. LenzThermal performance of solar concentrator/cavity receiver systems. Solar Energy, 34, pp. 135-142 (1985).

2. K.M.Faust, E.J. Plate EJ, M. Kuczera, . Experimental investigation on the convective losses from the cavity receiver of the project GAST. In:SAND81-8014 (P. F'allcone), Sandia National Laboratories, p.p 143-164 (1981).

3. R.Y. Ma, Wind effects on convective heat loss from a cavity receiver for parabolic concentrating solar collector. Contractor Report, Sandia National Laboratories, SAND92-7293, Albuquerque, New Mexico (1993).

4. D. A. Kugath, G. Drenker, and A. A. Koenig, Design and development of a paraboloidal dish solar collector for intermediate temperature service. Proc. ISES Silver Jubilee Congr., Vol. 1, p. 449-453 (1979).

5. M. Prakash, S. B. Kedare, J. K. Nayak, Investigations on heat losses from a solar cavity receiver, Solar Energy, 83, pp.157-170 (2009).

6. Shaun g-Ying Wu, Lan Xiao, Yiding Cao, YouRong Li. Convection heat loss from cavity receiver in parabolic dish solar thermal power system: A review. Solar Energy, 84, pp. 13421355 (2010).

7. Ka. Lok. Lee, Mehdi Jafarian, Farzin Ghanadi, Maziar Arjomandi, Graham J. Nathan, An investigation into the effect of aspect ratio on the 
heat loss from a solar cavity receiver. Solar Energy 149 , pp. 20-31 (2017).

8. T. Taumoepeau, S. Paitoonsurikarn, G. Hughes, and K. Lovegrove,."Experimental investigation of natural convection heat loss from a model solar concentrator cavity receiver," Journal of Solar Energy Engineering, vol. 126, pp. 801-807, (2004).

9. N. Sendhil Kumar and K. S. Reddy, "Numerical investigation of natural convection heat loss in modified cavity receiver for fuzzy focal solar dish concentrator," Solar Energy, vol. 81, no. 7, pp. 846-855 (2007).

10. M. Prakash, S. B.Kedare and J. K. Nayak, Determination of Stagnation and Convective Zones in a Solar Cavity Receiver, Int. J. Therm. Sci.2010; 49(4); 680-691 (2010). 